\title{
USO DA SEPARAÇÃO BOTÂNICA NA AVALIAÇÃO DA PORCENTAGEM DE CAPIM ANNONI 2 (Erasgrostis plana Ness) PRESENTE NA PASTAGEM EM UM SISTEMA SILVIPASTORIL NA REGIÃO DA CAMPANHA, RS
}

\author{
IVONE MARIA BARP PAIM VIEIRA'; SIDNEI JUNIOR SOUZA ROCHA ${ }^{2}$; \\ ALEXANDRE COSTA VARELLA ${ }^{3}$ MELISSA BATISTA MAIA ${ }^{4}$ \\ ${ }^{1} E M B R A P A C P P S U L$ - ivone.mbpvieira@gmail.com \\ 2EMBRAPA CPPSUL- rochasouzasidnei@gmail.com \\ ${ }^{3} E M B R A P A$ CPPSUL-Alexandre.varella@embrapa.br \\ ${ }^{4}$ EMBRAPA CPPSUL - melissa.maia@colaborador.embrapa.br
}

\section{INTRODUÇÃO}

Em meados do século $X X$ através da importação de sementes de gramíneas forrageiras, surgiu nos campos do sul do Brasil uma das mais graves invasões biológicas dessa região: o Campim Annoni (Eragrostis plana Ness) (FERREIRA; FILIPPI, 2010). Mesmo chegando como impureza, o Grupo Rural Annoni passou a produzir e comercializar suas sementes no RS e em outros Estados do Brasil, divulgando a espécie como uma forrageira excelente e revolucionária, pelo seu vigor e boa produção de massa verde e de sementes (REIS e COELHO, 2000). Um aspecto importante em relação à essa gramínea, que muito contribuiu para que a mesma se tornasse invasora em nossa região é a alta capacidade de produção de sementes pequenas e de fácil disseminação (MEDEIROS et al., 2006). Em função dos seus atributos biológicos, o capim-annoni-2 apresenta alta habilidade competitiva podendo modificar a estrutura e a diversidade da comunidade vegetal, alterando o seu equilíbrio. Com o tempo, a espécie torna-se dominante e a comunidade assume o aspecto de "monocultura" (REIS e COELHO, 2000).

Sistema silvipastoril ou de integração floresta-pecuária, "é uma modalidade dos sistemas agroflorestais e refere-se a um sistema de produção no qual espécies arbóreas e forrageiras são cultivadas em uma mesma unidade de área simultaneamente, com a presença de animais ruminantes" (VEIGA; SERRÃO, 1990). Segundo VARELLA (2008) esse sistema representa uma forma de uso da terra na qual as atividades de silvicultura e pecuária estão associadas gerando uma produção complementar pela interação de seus componentes.

Com relação ao controle da espécie, uma alta densidade de árvores pode exercer o controle de gramíneas com baixa tolerância à sombra. Costa et al. (2000), ao comparar espécies de gramíneas estivais sob duas densidades arbóreas de acácia negra (Acacia mearnsii De Wild.), em sistema silvipastoril sob pastejo contínuo, observaram uma tendência de diminuição do diâmetro das plantas de capim-annoni-2. Trabalhando na mesma área, Lucas (2004) verificou que no final do terceiro ano a população de plantas de capim-annoni-2 foi reduzida a zero. A integração pecuária - floresta é um dos temas de grande importância ao agronegócio brasileiro, tendo em vista que pode ser responsável por recuperar áreas degradas pela invasão de Capim Annoni.

\section{METODOLOGIA}

A área experimental está instalada no campo do Potreiro 25 da Embrapa Pecuária Sul, Bagé/RS, localizado na região da Campanha do Estado do Rio Grande do Sul. O delineamento experimental foi em parcelas subdivididas com 
duas repetições, nos quais as parcelas principais constam de diferentes condições de luminosidade sobre a pastagem nativa severamente infestada por Capim Annoni-2:

-Arborização com Eucalyptus grandis na densidade de 800 árvores por hectare (dispostos em linhas triplas);

-Arborização com E. grandis na densidade de 600 árvores por hectare (dispostos em linhas triplas);

-Sem arborização ou a pleno sol.

As sub parcelas constavam das seguintes estratégias de controle do Capim Annoni-2 em pastagem nativa do sub-bosque:

-Conservador, sem a introdução de forrageiras exóticas e com aplicações seletivas de herbicida no campo nativo, através da tecnologia "Campo Limpo" elaborada pela Embrapa Pecuária Sul;

-Intensiva, com introdução de forrageiras exóticas de inverno resistentes ao sombreamento (azevém anual + trevo vermelho c.v. E116 + cornichão c.v. São Gabriel).

A área total do experimento consiste em 34 hectares, sendo as unidades arborizadas compostas por uma área de 6 hectares cada (totalizando 24 ha) e a unidade experimental sem arborização composta por uma área de 5 hectares cada (totalizando 10ha). As árvores de eucalipto ( $E$. grandis) foram estabelecidas em fileiras triplas com espaçamento de $2 \mathrm{~m}$ entre plantas na linha e $3 \mathrm{~m}$ entre linhas e com 34m e 14m entre renques. No total, existem 12 potreiros.

Para avaliação da composição botânica foram cortadas mensalmente três amostras de $0,25 \mathrm{~m}^{2}$ por tratamento totalizando 36 amostras/mês no período de outubro de 2013 a outubro de 2015 (24 meses). As amostras foram pesadas a campo e levadas ao laboratório de forrageiras, onde após nova pesagem, foram separadas em 6 categorias: gramínea nativa, gramínea cultivada, leguminosa nativa, leguminosa cultivada, Capim Annoni e outras. A utilização deste método possibilitou quantificar a presença do Capim Annoni na composição da matéria seca das amostras.

Após este processo, as subamostras foram levadas à estufa, onde permaneceram por 72 horas para avaliação de matéria seca.

\section{RESULTADOS E DISCUSSÃO}

A porcentagem de Capim Annoni presente nas amostras das áreas melhoradas (tratamento intensivo) apresentou diminuição significativa (Gráfico 1). Passou de $26 \%$ na primavera de 2013 para $13,4 \%$ na primavera de 2015 . Na área nativa (de tratamento conservador) a porcentagem passou de $75,5 \%$ na primavera de 2013 para 18,5\% na primavera de 2015. A porcentagem de Capim Annoni presente nas amostras das áreas de pastagem melhoradas durante 0 período de avaliação foi inferior a porcentagem do mesmo nas áreas de pastagem natural. A altura média das árvores no ano de 2014 foi 2,36 m e em 2015 passou para $4,08 \mathrm{~m}$ de altura, o que pode ter influenciado para uma diminuição mais efetiva em 2015 influenciado pelo sombreamento mais efetivo devido à altura das árvores. $\mathrm{O}$ trabalho continua em andamento com pastejo contínuo. 
100,0

Porcentagem de Capim Annoni 2 nos tratamentos INTENSIVO e CONSERVADOR

90,0

80,0

70,0

60,0

50,0

40,0

30,0

20,0

10,0

0,0
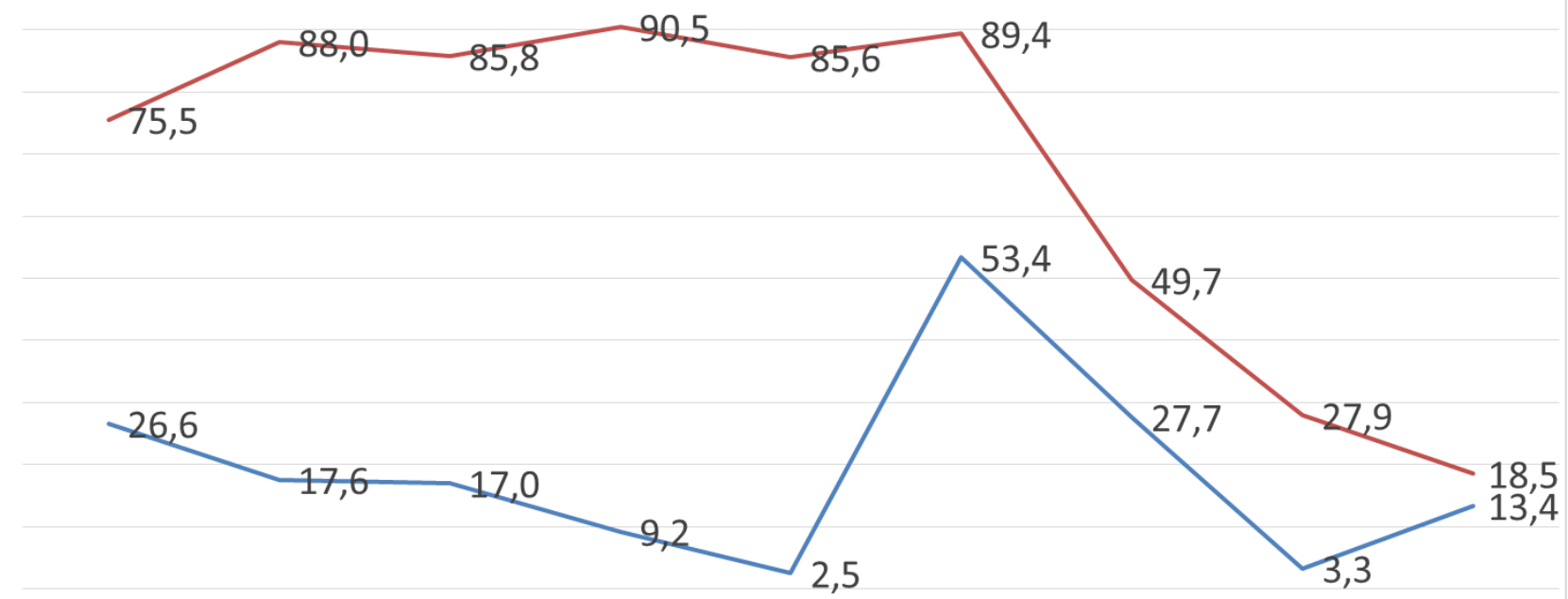

PRIM 13 VERÃO 14 OUTO 14 INV 14 PRIM 14 VERÃO 15 OUTO 15 INV 15 PRIM 15

- Intensivo -Conservador

Gráfico 1 - Porcentagem média de Capim Annoni 2 nas amostras coletadas de outubro de 2013 a outubro dos tratamentos INTENSIVO e CONSERVADOR.

\section{CONCLUSÕES}

Podemos concluir que as técnicas de manejo de um Sistema Silvipastoril aliadas ao melhoramento de pastagens, com introdução de forrageiras como o Trevo e o Cornichão, podem estar influenciando para a diminuição da presença de Capim Annoni na composição florística da pastagem que inicialmente se encontrava altamente degradada por esta planta invasora. 


\section{REFERÊNCIAS BIBLIOGRÁFICAS}

COSTA, J. A. A. da ; ROSA, L. M. G.; CASTILHOS, Z. M. S.; GUTERRES, E. ; SILVA, J. L. S. da Alterações no Perfil em Pastagens de Verão Submetida ao Pastejo em Sistema Silvipastoril com Acácia Negra (Acacia mearnsii De Wild.). In: REUNIÃO DA SOCIEDADE BRASILEIRA DE ZOOTECNIA, p .37., Viçosa, Anais, 2000.

FERREIRA, N. R.; FILIPPI, E. E. Reflexos econômicos, sociais e ambientais da invasão biológica pelo capim-annoni (Eragrostis plana nees) no Bioma Pampa. Cadernos de Ciência \& Tecnologia, Brasília, v. 27, n. 1/3, p. 47-70, jan./dez. 2010.

LUCAS, N. M. Desempenho Animal em Sistema Silvipastoril com Acácia-Negra (Acacia mearnsii De Wild.) e Rendimento de Matéria Seca de Cultivares de Panicum maximum Jacq. sob Dois Sistemas de Luz Solar. Porto Alegre, UFRGS, 2004. 127 p. Tese (Doutorado em Zootecnia) - UFRGS, 2004.

MEDEIROS R. B.; FOCHT, T. Invasão, prevenção, controle e utilização do Capim-annoni-2 (eragrostis plana nees) no Rio Grande do Sul, Brasil. PESQ. AGROP. GAÚCHA, PORTO ALEGRE, v.13, n.1-2, p.105-114, 2007.

MEDEIROS, R. B. ; FOCHT, T ; FREITAS, M. R.; MENEGON, L. L. Longevidade de Sementes de Capim-Annoni-2 em Solo de Campo Natural. In: REUNIÃO DO GRUPO TÉCNICO EM FORRAGEIRAS DO CONE SUL, 21., 2006, Pelotas, Palestras e Resumos... 2006.

REIS, J. C. L. , COELHO, R.W. Controle do Capim Annoni-2 em Campos Naturais e Pastagens. Pelotas: EMBRAPA Clima Temperado, 21p. EMBRAPA Clima Temperado, Circular Técnica, 22, 2000.

VARELLA, A.C.; RIBASKI, J.; SILVA, V. P.; SOARES, A. B.; MORAES, A.; MORAIS, H.; SAIBRO, J. C.; BARRO, R .S.; POLI, C. H. E. C.; PAULINO, B. M. Recomendações para a escolha e manejo de plantas forrageiras em sistemas silvipastoris no Sul do Brasil. Bagé: Embrapa Pecuária Sul, 2008.

VEIGA, J. B.; SERRÃO, E. A. S. Sistemas silvipastoris e produção animal nos trópicos úmidos: a experiência da Amazônia brasileira. Campinas: SBZ: FEALQ, 1990. p. 37-68. 